\title{
PROPENSÃO À dÍVIDA NO CARTÃO DE CRÉDITO: QUAIS SÃO OS ASPECTOS DETERMINANTES?
}

PROPENSITY TO DEBT ON CREDIT CARD: WHAT ARE THE ISSUES DETERMINANTS?

\section{Kelmara Mendes Vieira}

kelmara@terra.com.br

Universidade Federal de Santa Maria, Santa Maria/RS, BRASIL

\section{Franciele Reis Kunkel}

francikunkel@hotmail.com

Universidade Federal de Santa Maria, Santa Maria/RS, BRASIL

\section{Ana Luiza Paraboni}

anyparaboni@hotmail.com

Universidade Federal de Santa Maria, Santa Maria/RS, BRASIL

\section{Resumo}

O cartão se tornou um dos principais instrumentos financeiros em razão da crescente facilidade de acesso e sua propagação, devido à multifuncionalidade. Este estudo teve como objetivo construir um indicador de propensão à dívida no cartão de crédito, assim como avaliar a influência dos aspectos demográficos, culturais e das características do cartão. Foram aplicados 1.831 questionários no Rio Grande do Sul, Maranhão e Minas Gerais. Os resultados, no geral, indicam que os respondentes sabem utilizar esse meio de pagamento de forma responsável, e as seguintes variáveis apresentaram diferenças significativas entre os grupos: dependentes, filhos, escolaridade, raça, ascendência, número de cartões, percentual da renda gasta no cartão e valor do gasto mensal. Por fim, observou-se que a propensão à dívida no cartão de crédito pode ser influenciada por: dependentes, valor aproximado da dívida atual no cartão, percentual da renda gasta com o pagamento do mesmo e limite do cartão de crédito.

Palavras-chave: Cartão de crédito. Propensão à dívida. Variáveis sociodemográficas.

\begin{abstract}
Credit card has become one of the most important financial instruments due to its growth accessibility and spread, on account of its multifunctionality. This study had, as its objective, build a propensity indicator to debt in credit card, as well as, evaluate the influence of demographic and cultural aspects, and credit cards characteristics. To reach its objective, 1.831 questionnaires were applied in Rio Grande do Sul, Maranhão and Minas Gerais. The results indicate, in general, that the respondents know how to use credit cards in a responsible way, and the variables that presented significant difference among groups were: having dependents, children, schooling level, race, descent, number of cards, the percentage of income spent in credit cards and the value spent monthly. Finally, the propensity to debt in credit card was observed, which can be influenced by having dependents, the actual debt in credit cards, the percentage of income spent with its payment and the credit card limit for shopping.
\end{abstract}

Keywords: Credit card. Propensity to debt. Sociodemographic variables. 


\section{Introdução}

Os talões de cheques estão sendo, cada vez mais, substituídos por cartões de débito e crédito pelos brasileiros. De acordo com as projeções do Banco Central, até o final de 2014, 4,9 milhões de transações serão realizadas via cartão de crédito, o que representa um crescimento de $11,4 \%$ sobre o ano anterior. Além disso, o número de cartões de crédito ativos em 2013, se comparado com 2012, também apresentou crescimento, registrando alta de 7,3\%.

Para autores como Bertaut e Haliassos (2005), o cartão de crédito se tornou um dos principais instrumentos financeiros utilizados nos dias atuais, em razão da crescente facilidade de acesso a esse meio de pagamento e sua consequente propagação diante do consumidor. Isso acontece devido a multifuncionalidade do cartão, tendo em vista que ele funciona como uma ferramenta de pagamento e, ainda, como recurso de crédito (KIM; DEVANEY, 2001), ou seja, promove facilidade, conveniência e segurança nas transações (BERTAUT; HALIASSOS, 2005).

Por outro lado, o usuário que não souber gerir o cartão ou que for usá-lo de forma imprópria pode contrair dívidas, afetando tanto a saúde financeira familiar (NORVILITIS et al., 2006; MACGEE, 2012) quanto o bem estar físico e mental do indivíduo (LYONS, 2004). Nesse sentido, para a Confederação Nacional do Comércio de Bens, Serviços e Turismo (CNC, 2014), o cartão de crédito está sendo apontado como o maior vilão do endividamento, considerando que em fevereiro de 2014, 62,7\% das famílias mostraram-se endividadas, contra $61,5 \%$ do mesmo período de 2013. Além disso, 6,7\% desses indivíduos acabam utilizando o crédito rotativo ou parcelando a fatura com juros, visto que não conseguem honrar os compromissos financeiros (ABECS, 2014). Para Wang, Lu e Malhotra (2011), o cartão de crédito acaba acarretando em dívidas em razão, principalmente, da eliminação da necessidade imediata do dinheiro, ou seja, o usuário não precisa discorrer de certa quantia de dinheiro no momento exato da compra, gerando uma ilusão de renda.

Apesar de a dívida no cartão de crédito já ter sido investigada através de diferentes aspectos, ainda não existe um consenso quanto as suas efetivas causas e consequências. Nesse sentido, a corrente das finanças comportamentais vem procurando explorar quais são os fatores que possam influenciar esse acontecimento financeiro (KEESE; SCHMITZ, 2010), sendo que a maior problemática está associada ao nível de responsabilidade financeira no uso do cartão de crédito e aos prováveis riscos de problemas financeiros e psicológicos decorrentes do mau gerenciamento (LYONS, 2004). Nesse contexto, torna-se relevante identificar os aspectos que levam os indivíduos ao mau gerenciamento do cartão de crédito. Diversos pesquisadores tem afirmado que a dívida no cartão de crédito além de ser influenciada pelo ambiente socioeconômico (taxa de juros e inflação) e por condições financeiras do indivíduo é afetada por características pessoais como: idade, estágio do ciclo de vida, ocupação, escolaridade e, ainda, por fatores comportamentais e psicológicos como: as atitudes em relação ao dinheiro, à dívida e ao crédito, o senso de controle, o nível de autoestima e de otimismo, assim como os valores e as expectativas pessoais (DAVIES, LEA, 1995; KIM, DEVANEY, 2001; CHIEN, DEVANEY, 2001; NORVILITIS, SZABLICKI, WILSON, 2003; KEESE, 2010; WANG, LU, MALHOTRA, 2011; TAN, YEN, LOKE, 2012).

Sendo assim, o objetivo principal deste estudo é construir um indicador de comportamento de propensão à dívida no cartão de crédito, assim como avaliar a influência dos aspectos demográficos, culturais e das características do cartão de crédito na propensão à dívida no cartão.

\section{Comportamento de propensão à dívida no uso do cartão de crédito}

Estimativas do Banco Central revelam que no ano de 2014, o volume de transações realizadas via cartão de crédito fechará com um aumento de 11,4\%, representando 4,9 bilhões de transações. Além disso, aproximadamente 146 milhões de pessoas no país, o que equivale a $77 \%$ da população, possuem e utilizam cartão de crédito. Para Bertaut e Haliassos (2005) e Lee e Kwon (2002), esta popularidade está relacionada à conveniência, segurança na realização das transações e a flexibilidade de pagamento que o cartão proporciona. No entanto, autores como Lee e Kwon (2002) e Park e Burns (2005) afirmam que esse significativo aumento na utilização desse meio de pagamento, assim como a crescente importância do cartão, seja como meio de pagamento ou ferramenta de crédito, têm contribuído 
para intensificar a preocupação do mercado e da academia quanto aos comportamentos mantidos pelo indivíduo no uso dessa nova ferramenta.

O uso do cartão de crédito, se analisado através do comportamento do consumidor, pode apresentar dois lados distintos. O uso responsável do cartão de crédito proporciona ao indivíduo um meio conveniente de pagamento, uma ferramenta útil para gestão dos recursos financeiros, obtenção de recursos em situações de emergência e um meio de estabelecer um bom histórico de crédito (KIM, DEVANEY, 2001; BERTAUT, HALIASSOS, 2005; TAN, YEN, LOKE, 2011). Por outro lado, se comparado ao uso do dinheiro, o uso do cartão estimula os gastos, leva a maior imprudência, pois não exige o desembolso imediato de recursos e, ainda, reforça o problema do comportamento de compra compulsiva, acarretando, consequentemente, no endividamento pessoal e familiar (ROBERTS; JONES, 2001).

De acordo com o Dicionário de Negócios, o endividamento no cartão de crédito corresponde a um tipo de passivo a descoberto, sendo constituído mediante um empréstimo rotativo de curto prazo, sendo que dependendo do nível da dívida, os indivíduos podem comprometer uma parcela significativa de sua renda, tornando-se incapazes de honrar os compromissos financeiros assumidos. Nesse sentido, tem-se uma situação de sobre-endividamento, o qual pode ser ativo ou passivo. Segundo Zerrenner (2007), o sobre-endividamento ativo acontece quando o indivíduo contribui ativamente para se colocar em uma situação de impossibilidade de pagamento. Por outro lado, no passivo, essa impossibilidade de pagamento resulta de circunstâncias não controláveis, como no caso de uma doença, por exemplo. Para autora, o sobre-endividamento impacta negativamente não apenas sobre as finanças pessoais e familiares, mas também sobre a economia como um todo, tendo em vista que a proliferação dos casos de inadimplência afeta o volume de crédito, acabando por impactar no crescimento econômico.

De acordo com Lee e Kwon (2002), os usuários de cartão de crédito podem ser divididos em dois grupos: usuários de conveniência e usuários do rotativo. Os usuários de conveniência tendem a utilizar o cartão como um meio de pagamento, quitando o valor integral da fatura no vencimento e evitando, dessa forma, os encargos financeiros. No entanto, os usuários do rotativo utilizam o cartão como um meio de financiamento, não quitando o valor integral da fatura e, por esse motivo, incorrendo nos juros sobre o saldo devedor.

Com o objetivo de identificar as características sociodemográficas determinantes do uso do cartão de crédito, Lee e Kwon (2002) investigaram 4.309 cidadãos americanos. Fundamentados na classificação proposta por Lee e Hogarth (1999) e na análise de regressão logística multinomial, os autores observaram que indivíduos negros, com menor nível de renda e escolaridade, maior faixa etária, baixo limite de crédito na conta bancária, maior nível de endividamento, histórico de crédito ruim e atitudes favoráveis frente ao uso do cartão são mais propensos a serem usuários do rotativo, ou seja, utilizar o cartão como instrumento de financiamento.

Além disso, Teoh, Chong e Yong (2013) visaram explorar os fatores que afetam o comportamento de gasto de usuários de cartão de crédito. Através da realização de uma pesquisa cross-section administrada com 150 usuários de cartão na população da Malásia, os autores verificaram que indivíduos mais velhos, casados e com maior nível de renda tendem a gastar de forma mais descontrolada no cartão de crédito. No entanto, observaram que indivíduos com atitudes positivas frente ao dinheiro, como vontade para pagar as contas e conscientização sobre o valor das dívidas tendem a apresentar comportamentos mais responsáveis na hora de utilizar o cartão.

Os estudos também têm buscado relatar as principais consequências decorrentes da má utilização ou má gestão do cartão. Problemas de ordem financeira, como a maior propensão ao endividamento (LEE, KWON, 2002; NORVILITIS, SZABLICKI, WILSON, 2003) e o risco de falência (ROBERTS; JONES, 2001), problemas de ordem comportamental, como o agravamento do comportamento de compra compulsiva (ROBERTS, JONES 2001; PARK, BURNS, 2005; JOJI, RAVEENDRAN, 2008; NORUM, 2008) e problemas de ordem psicológica, como a redução do nível de bem-estar e a depressão (NORVILITIS et al., 2006) vem sendo apontados como consequências diretas da má gestão do cartão de crédito.

De acordo com Lie et al. (2010), a experiência pessoal com o cartão de crédito cria associações positivas com o consumo, levando ao aumento dos gastos. 
Além disso, os titulares de cartão de crédito tendem a esquecer ou subestimar o preço dos bens, assim como o valor total gasto durante as atividades de compra, levando ao problema do consumo excessivo (DURKIN, 2000), ao aumento das despesas e, ainda, ao endividamento (TEOH, HONG, YONG, 2013).

\section{Influência dos aspectos demográficos, culturais e das características do cartão de crédito sobre o comportamento de propensão à divida no uso do cartão de crédito}

Os aspectos demográficos relacionados ao comportamento de propensão à dívida no uso do cartão são analisados a partir de oito variáveis: gênero, idade, estado civil, composição familiar (dependentes e filhos), nível de escolaridade, raça, ocupação e renda. O aspecto cultural é representado pela variável ascendência. As características do cartão de crédito, por sua vez, são representadas por cinco variáveis: número de cartões de crédito, conhecimento do valor da taxa de juros, limite do cartão de crédito, percentual da renda gasta e valor aproximado do gasto mensal no cartão de crédito. $\mathrm{Na}$ sequência é realizada uma breve revisão teórica sobre a influência de cada uma das variáveis sobre o comportamento de propensão à dívida no uso do cartão de crédito.

Ao investigar a relação entre a variável gênero e a dívida no cartão de crédito, percebe-se que não existe um consenso na literatura. Wang, Lu e Malhotra (2011), visando identificar as variáveis demográficas, atitudinais, de personalidade e as características do cartão de crédito que influenciam na dívida no cartão, verificaram que os homens tendem a endividar-se com maior frequência que as mulheres. Segundo os autores, isso acontece porque as mulheres são mais prudentes em suas decisões financeiras, apresentam melhor organização e planejamento do orçamento financeiro (BAEK; HONG, 2004) e são mais avessas ao risco (KEESE, 2010). Mendes-Da-Silva, Nakamura e Moraes (2012), a fim de identificar e caracterizar os estudantes com maior propensão à má gestão ou mau uso do cartão de crédito, corroboraram os achados de Wang, Lu e Malhotra (2011).

Por outro lado, Lyons (2004), visando identificar as características associadas ao comportamento de risco financeiro, verificou que as mulheres são mais predispostas a deixar de pagar a fatura integral do cartão por um período igual ou superior a dois meses. Além disso, em outro estudo realizado pela pesquisadora com o objetivo de descrever o uso do cartão de crédito, identificar os estudantes mais propensos à má gestão do cartão e, ainda, identificar as principais consequências advindas do uso irresponsável do cartão, verificou-se que as mulheres são mais propensas a i) ter dívidas no cartão de crédito superiores a $\$ 1.000,00$ dólares, ii) não pagar a fatura integral por um período igual ou superior a 2 meses e, iii) estourar o limite do cartão de crédito (LYONS, 2007).

Com relação à variável demográfica idade, representativa parcela das pesquisas aponta para a maior probabilidade de indivíduos jovens utilizarem o cartão de crédito de forma indevida e contraírem dívidas. Norvilitis et al. (2006) em pesquisa desenvolvida com o propósito de explorar as causas e consequências da dívida no cartão de crédito, investigou 448 estudantes de cinco universidades. Através do estudo, verificou que pessoas mais jovens tendem a apresentar maior taxa de endividamento em relação a pessoas mais velhas, devido à expectativa positiva de renda futura, ou seja, os jovens que acreditam que no futuro terão um alto padrão de renda são mais favoráveis ao crédito e tolerantes ao endividamento.

Quanto ao estado civil, os indivíduos casados aparecem como mais propensos a apresentarem maiores níveis de dívida no cartão de crédito. Lyons (2004), em pesquisa desenvolvida com o objetivo de identificar os fatores que afetam, significativamente, a propensão dos jovens em realizar uma má utilização e/ou má gestão do cartão de crédito, concluiu que os indivíduos casados são mais propensos a contrair dívidas no cartão de crédito e a possuir dívidas com valor superior a $\$ 1.000,00$.

No que tange a composição familiar, que se refere à quantidade de membros em uma família, Bertaut e Haliassos (2005), em estudo com o propósito de documentar características de uso do cartão de crédito e de débito ao longo do tempo, concluíram que famílias com mais de duas crianças tendem a apresentar maior propensão à dívida no cartão de crédito. Além disso, visando investigar as características dos usuários de cartão de crédito e distingui-los entre usuários de conveniência e usuários do crédito rotativo, Tan, Yen 
e Loke (2011) verificaram que entre os indivíduos que detêm cartão de crédito, aqueles com dependentes e filhos apresentam maior nível de dívida, se contrastados com aqueles que não possuem.

No que se refere ao nível de escolaridade, Baek e Hong (2004), em pesquisa com o propósito de examinar fatores relacionados à dívida no cartão de crédito e ao parcelamento da dívida, constataram que famílias cujo chefe possuía alto grau de escolaridade apresentavam maior propensão a possuir pelo menos um cartão de crédito e a endividar-se, se comparadas a famílias cujo chefe possuía menor nível de escolaridade. De acordo com Kim e DeVaney (2001), por acreditarem que a obtenção de recursos futuros elevados (nesse caso, alto nível de escolaridade) geram rendimentos futuros maiores, os indivíduos tendem a contrair dívidas mais frequentemente.

Analisando a variável raça, os estudos tem constatado a maior probabilidade de indivíduos não-brancos apresentarem os piores comportamentos quanto ao uso do cartão de crédito. Lyons (2004) e Joo e Grable (2006) verificaram que os grupos étnicos minoritários são mais propensos a utilizar o crédito rotativo do cartão de crédito. Lyons $(2004,2007)$ em pesquisas realizadas com os objetivos de identificar os fatores que afetam a propensão dos jovens em realizar uma má utilização e/ou má gestão do cartão de crédito e fornecer insights quanto às práticas de gestão financeira e gestão do crédito mantidas por universitários, respectivamente, verificou que indivíduos negros, se contrastados com pessoas não-negras, são mais predispostos a possuir dívidas com valor superior a $\$$ 1.000,00 dólares e a deixar de pagar a fatura integral do cartão por um período igual ou superior a dois meses.

Para analisar aspectos relacionados ao trabalho, utilizou-se a variável ocupação que se refere ao fato de os indivíduos estarem empregados, desempregados ou não trabalharem. De acordo com Keese (2010), a ocupação exerce impacto significativo sobre o comportamento de dívida no uso do cartão de crédito, dado que pessoas desempregadas exibem expectativas mais pessimistas em relação ao futuro, fazendo com que os mesmos sejam desfavoráveis ao uso do crédito e apresentem menor propensão ao endividamento. Nesse sentido, Chien e DeVaney (2001), em estudo realizado com 4.305 pessoas nos Estados Unidos com o objetivo de verificar quais variáveis demográficas, econômicas e atitudinais atuam como determinantes do uso do cartão de crédito e do uso de empréstimos convencionais, encontraram que indivíduos empregados apresentam maior probabilidade de possuir cartão de crédito e de endividar-se, se confrontados a indivíduos desempregados ou pessoas que não trabalham.

No que se refere à renda, verifica-se que não há consonância entre os resultados das investigações. Com a finalidade de identificar os fatores determinantes da quantidade de dívida mantida por usuários de cartão de crédito, Kim e DeVaney (2001) constataram que indivíduos com maior nível de renda apresentam maiores níveis de endividamento, devido, possivelmente, a associação positiva entre a elevação da renda e a elevação do limite do cartão de crédito, uma vez que o aumento do rendimento pessoal abre a possibilidade de elevar o limite do cartão de crédito, operação essa que pode aumentar os níveis de consumo e endividamento. Por outro lado, Chien e Devaney (2001), ao realizarem uma survey com o objetivo de verificar as variáveis determinantes do uso do cartão de crédito e do uso de empréstimos convencionais, verificaram que quanto maior a renda auferida pelo indivíduo, melhor é o comportamento do indivíduo no uso do cartão.

A investigação da relação da variável ascendência com o comportamento de uso do cartão de crédito tem apontado resultados divergentes quando consideradas diferentes ascendências. Tan, Yen e Loke (2011), ao investigarem 938 indivíduos, concluíram que a etnia é um fator determinante para a explicação do número de cartões de crédito e do endividamento, sendo que os chineses, se comparados aos indianos apresentam maior predisposição a possuir cartão de crédito e menor propensão ao endividamento. Lyons (2007), por sua vez, em estudo realizado com 26.896 estudantes, observou que os hispânicos, se confrontados às demais etnias são mais tendentes a apresentar maiores níveis de dívida.

Segundo Wang, Lu e Malhotra (2011), o número total de cartões de crédito está positivamente relacionado com o maior uso e endividamento. Em uma pesquisa realizada com 1.410 usuários de cartão de crédito, os autores verificaram que indivíduos que possuem maior número de cartões, se comparados aos demais, apresentam um pior comportamento de uso do cartão. Para Kim e DeVaney (2001), a disponibilidade de recursos financeiros extras incentivam os indivíduos 
a consumir mais e, por consequência, a gastar mais, fazendo com que a posse de um maior número de cartões de crédito desempenhe um importante papel no aumento do nível de dívida.

Com relação ao conhecimento do valor da taxa de juros do cartão de crédito, verifica-se uma relação inversa entre essa variável e o comportamento de uso no cartão. Autores como Mendes-Da-Silva, Nakamura e Moraes (2012) observaram que indivíduos que conhecem o valor da taxa de juros cobrada em caso de utilização do crédito rotativo são menos predispostos a possuir comportamentos de risco de má gestão do cartão como, por exemplo, pagar somente uma parcela da fatura e/ou possuir dívidas com valor superior a $\mathrm{R} \$ 1.000,00$.

Quanto ao limite do cartão de crédito, Kim e DeVaney (2001) e Wang, Lu e Malhotra (2011) sugerem que o mesmo está positivamente relacionado com o mau uso do cartão de crédito, tendo em vista a chamada "ilusão de renda", gerada pelo maior limite, sendo visto como um complemento do rendimento familiar. Kim e DeVaney (2001) verificaram que a presença de 1 dólar adicional no limite do cartão gera uma elevação média de \$0,09 dólares no nível de endividamento. Além disso, Wang, Lu e Malhotra (2011) concluíram que portadores de cartão de crédito com limite superior a U $\$ 1.489,00$ dólares possuíam maior volume de dívidas se comparados àqueles cujo limite de crédito era de U\$446,00 dólares.

Ao verificar o percentual da renda e/ou o valor mensal gasto com compras no cartão de crédito, Moreira (2000) afirma que quanto maior for o descontrole dos gastos, maior será a probabilidade de contrair dívidas, tendo em vista que aqueles indivíduos que gastam boa parte de seus rendimentos mensais com compras no cartão de crédito, provavelmente terão dificuldades para cumprir com os demais compromissos financeiros e, ainda, terão dificuldades para quitar o valor integral da fatura. A Figura 1 apresenta as relações esperadas.

Figura 1. Síntese das pressuposições acerca da relação existente entre os aspectos demográficos, aspectos culturais, características do cartão de crédito e a dívida no cartão de crédito

\begin{tabular}{|c|c|}
\hline Variável & Pressuposição \\
\hline Gênero & Relação indefinida - Existe diferença de dívida no cartão de crédito se considerado o gênero. \\
\hline Idade & Relação negativa - Indivíduos mais jovens são mais propensos a exibir dívidas no cartão de crédito. \\
\hline Estado civil & Indivíduos casados tendem a apresentar maior nível de dívida no cartão de crédito \\
\hline Composição familiar & $\begin{array}{l}\text { Relação positiva - Indivíduos com dependentes/com filhos são mais propensos a exibir dívidas no } \\
\text { cartão de crédito. }\end{array}$ \\
\hline Nível de escolaridade & $\begin{array}{l}\text { Relação positiva - Indivíduos com maior nível de escolaridade são mais propensos a exibir dívidas no } \\
\text { cartão de crédito. }\end{array}$ \\
\hline Raça & $\begin{array}{l}\text { Relação indefinida - Indivíduos classificados como não-brancos são mais propensos a exibir dívidas } \\
\text { no cartão de crédito. }\end{array}$ \\
\hline Ocupação & Relação positiva - Indivíduos ocupados são mais propensos a exibir dívidas no cartão de crédito. \\
\hline Renda & Relação indefinida - Existe diferença de dívida no cartão de crédito se considerada a renda. \\
\hline Ascendência & Relação indefinida - Existe diferença de dívida no cartão de crédito se considerada a ascendência. \\
\hline $\begin{array}{l}\text { Número de cartões de } \\
\text { crédito }\end{array}$ & $\begin{array}{l}\text { Relação positiva - Indivíduos detentores de um maior número de cartões de crédito são mais } \\
\text { propensos a exibir dívidas no cartão de crédito. }\end{array}$ \\
\hline $\begin{array}{l}\text { Conhecimento do valor } \\
\text { da taxa de juros }\end{array}$ & $\begin{array}{l}\text { Relação negativa - Indivíduos que conhecem o valor da taxa de juros são menos propensos a exibir } \\
\text { dívidas no cartão de crédito. }\end{array}$ \\
\hline $\begin{array}{l}\text { Valor do limite do cartão } \\
\text { de crédito }\end{array}$ & $\begin{array}{l}\text { Relação positiva - Indivíduos detentores de um maior limite de crédito são mais propensos a exibir } \\
\text { dívidas no cartão de crédito. }\end{array}$ \\
\hline $\begin{array}{l}\text { Percentual da renda e } \\
\text { valor mensal gasto no } \\
\text { cartão de crédito }\end{array}$ & $\begin{array}{l}\text { Relação positiva - Quanto maior o valor mensal da renda gasto no cartão de crédito maior a } \\
\text { probabilidade de endividamento. }\end{array}$ \\
\hline
\end{tabular}

Fonte: Elaborado pelos autores (2014). 


\section{Método}

Visando a atingir os objetivos do estudo, realizou-se uma pesquisa de caráter exploratório e, como estratégia de pesquisa, efetuou-se uma survey. Mediante a utilização de tais meios, utilizou-se como instrumento de coleta de dados um questionário estruturado.

A população alvo do estudo foi composta por toda a população brasileira usuária de cartão de crédito, sendo que de acordo com os dados divulgados pelo Serviço de Proteção ao Crédito (SPC Brasil, 2013), o número de brasileiros que utilizam cartão de crédito já corresponde a $77 \%$ da população ${ }^{1}$, ou seja, corresponde a, aproximadamente, 147 milhões de pessoas. Dessa forma, considerando um nível de confiança de 95\% e um erro amostral de 2,5\% obteve-se uma amostra final de 1.538 indivíduos. Pela dificuldade em aplicar os questionários em todo o território nacional, definiu-se a critério dos pesquisadores que o estudo seria realizado em três estados, sendo escolhidos, por conveniência, os Estados do Rio Grande do Sul, Minas Gerais e Maranhão. A decisão de investigar esses três estados está atrelada a diversidade econômica, cultural e social encontrada. Segundo a literatura financeira e comportamental, fatores como a raça, a ascendência e os traços culturais, os quais variam significativamente entre os Estados pesquisados, podem contribuir para a explicação do maior ou menor grau de endividamento dos indivíduos.

Os questionários foram aplicados de forma aleatória, em ambiente externo, através do contato com os moradores dispostos a participar do estudo. Além do questionário, foi entregue o Termo de Consentimento Livre e Esclarecido, documento este que garante a confidencialidade das informações cedidas pelo respondente, cumprindo com as exigências do Comitê de Ética da UFSM.

O processo de coleta de dados, iniciou-se no mês de abril de 2013 estendendo-se até o mês de setembro. Ao final da pesquisa foram coletados 1.831 instrumentos válidos, número esse, superior ao previamente estabelecido. O questionário, composto por 3 blocos de perguntas, apresenta questões abertas e fechadas que questionam o respondente quanto ao seu perfil, aos aspectos relacionados ao uso do cartão de crédito e relacionados a dívida no cartão.

$\mathrm{Na}$ parte inicial do questionário estão elencadas 8 questões que abordam distintos aspectos referentes ao uso do cartão de crédito. Tais questões foram adaptadas de estudos desenvolvidos por Kim e DeVaney (2001), Wang, Lu e Malhotra (2011), Disney e Gathergood (2011) e Mendes-Da-Silva, Nakamura e Moraes (2012).

Em seguida, o bloco de questões relacionadas à dívida no cartão de crédito teve por finalidade analisar a propensão do indivíduo em tornar-se inadimplente no cartão. Para mensurar tal fator, utilizou-se uma escala de 5 pontos (onde 1 corresponde a nunca e 5 corresponde a sempre) contendo 6 questões desenvolvidas com base em Wang, Lu e Malhotra (2011).

$\mathrm{Na}$ última seção estão listadas as questões referentes ao perfil do respondente, representadas por aspectos demográficos, culturais e econômicos. Tais questões, de múltipla escolha, foram elaboradas pelos autores seguindo a classificação fornecida pelo IBGE.

A análise dos dados foi realizada com o auxílio do software SPSS 17.0® e Eviews 7.0. Em um primeiro momento, realizou-se a estatística descritiva dos dados com o objetivo de determinar o perfil dos respondentes e identificar os aspectos referentes ao uso do cartão de crédito. Posteriormente, analisou-se a estatística descritiva da dívida no cartão de crédito, a fim de identificar média, mediana e desvio padrão. Em seguida, aplicaram-se os testes de diferença de média, teste $t$ de Student (Teste $t$ ), utilizado para comparar duas médias e a análise de variância (ANOVA), que compara as médias de mais de dois grupos simultaneamente, para analisar a influência das variáveis demográficas, culturais e das características do cartão de crédito sobre o comportamento de propensão à divida no uso do cartão.

Por fim, com o intuito de verificar a influência dos aspectos demográficos, culturais e das características do cartão de crédito sobre a propensão à dívida no cartão de crédito, foi realizada uma análise de regressão linear múltipla, através do método dos Mínimos Quadrados Ordinários (MQO). Segundo Hair et al. (2010), a regressão linear visa analisar a relação entre uma única variável dependente, neste caso, a dívida no cartão de crédito, com as variáveis independentes: percentual de renda mensal gasto com o pagamento do cartão de crédito; valor aproximado do gasto mensal em todos os cartões de crédito; valor aproximado da dívida atual no cartão de crédito, devido ao não pagamento da fatura integral; limite nos cartões de 
crédito; renda mensal líquida aproximada; dummy de gênero, de dependentes, de escolaridade, de estado civil e de ocupação. Para a construção da variável dependente, dívida no cartão de crédito, utilizouse a média das respostas, de cada entrevistado, das variáveis formadoras do fator.

Todos os modelos foram estimados utilizando a técnica White Heteroskedasticity-Consistent Standard Errors $\&$ Covariance, a qual corrige os erros-padrões e covariâncias, tornando-os consistentes com o pressuposto de não-heterocedasticidade.

\section{Resultados e discussões}

Esta análise está dividida em quatro seções, sendo apresentados na primeira parte o perfil da amostra, representado por meio de variáveis demográficas e socioeconômicas e, os aspectos relacionados ao uso do cartão de crédito. Na segunda seção buscouse identificar, a partir da escala quantitativa, as atitudes dos respondentes em relação a propensão ao endividamento no uso do cartão. Em seguida, aplicaram-se os testes de diferença de média, teste $t$ de Student (Teste $t)$, utilizado para comparar duas médias e a análise de variância (ANOVA), que compara as médias de mais de dois grupos simultaneamente. Por fim, buscou-se analisar a influência dos aspectos demográficos, culturais e das características do cartão de crédito no construto pesquisado, atendendo, assim, ao objetivo geral do estudo. Os resultados obtidos, a partir da análise dos questionários, são apresentados nas seções subsequentes.

Em relação ao número de respondentes, foram investigados ao total 1.831 usuários de cartão de crédito distribuídos entre os Estados do: i) Rio Grande do Sul, que contou com a participação de 945 respondentes, ii) Maranhão, representado por 602 indivíduos e, iii) Minas Gerais, que contou com a participação de 284 usuários de cartão de crédito.

Com base nos resultados, conclui-se que a amostra foi composta por $59,1 \%$ de respondentes do gênero feminino e 40,1\% do gênero masculino, possuindo, em média, 31 anos de idade. Quanto ao estado civil, predominaram os indivíduos solteiros $(60,9 \%)$, seguidos pelos casados $(33,2 \%)$. No que se refere à posse de dependentes, grande parte $(71,5 \%)$ alegou não ter dependentes financeiros. Dentre a parcela que possui, 52,3\% tem somente um dependente e menos de $13 \%$ apresentam três ou mais dependentes. Sobre o fato de ter ou não filhos, obteve-se resultado similar à questão da posse de dependentes, uma vez que a maior parcela $(67,5 \%)$ afirmou não ter filhos. Considerando a parcela de respondentes com filhos, a maioria possui um $(46,1 \%)$ ou no máximo dois $(37,3 \%)$. Uma das possíveis explicações para o baixo número de indivíduos com dependentes e/ou filhos, é o fato de a amostra ser constituída, predominantemente, por sujeitos solteiros e relativamente jovens (média de 31 anos). Outra explicação pode estar atrelada à decisão das famílias modernas em terem seus filhos mais tardiamente ou ainda a terem um menor número de filhos, como demonstra o censo demográfico realizado no ano de 2010 pelo IBGE, o qual revelou uma redução na taxa de fecundidade de 2,38 (resultado obtido pelo censo demográfico realizado no ano 2000) para 1,90 filhos por mulher brasileira. A Tabela 1 apresenta os resultados. 
Tabela 1 . Perfil dos respondentes através das variáveis: gênero, estado civil, número de dependentes, número de filhos, nível de escolaridade, raça, ascendência, ocupação e renda

\begin{tabular}{|c|c|c|c|}
\hline Variável & Alternativas & Frequência & Percentual \\
\hline \multirow{2}{*}{ Gênero } & Masculino & 749 & 40,9 \\
\hline & Feminino & 1.082 & 59,1 \\
\hline \multirow{4}{*}{ Estado civil } & Solteiro (a) & 1.115 & 60,9 \\
\hline & Casado (a) & 607 & 33,2 \\
\hline & Separado (a) & 80 & 4,4 \\
\hline & Viúvo (a) & 20 & 1,1 \\
\hline \multirow{2}{*}{ Possui dependentes } & Não & 1.309 & 71,5 \\
\hline & $\operatorname{Sim}$ & 522 & 28,5 \\
\hline \multirow{3}{*}{ Quantos dependentes } & 1 & 273 & 52,3 \\
\hline & 2 & 183 & 35,1 \\
\hline & 3 ou mais & 66 & 12,6 \\
\hline \multirow{2}{*}{ Possui filhos } & Não & 1.235 & 67,5 \\
\hline & Sim & 596 & 32,5 \\
\hline \multirow{3}{*}{ Quantos filhos } & 1 & 274 & 46,1 \\
\hline & 2 & 222 & 37,3 \\
\hline & 3 ou mais & 100 & 16,6 \\
\hline \multirow{8}{*}{ Nível de escolaridade } & Ensino fundamental & 103 & 5,6 \\
\hline & Ensino médio & 478 & 26,1 \\
\hline & Ensino superior & 806 & 44,0 \\
\hline & Curso técnico & 110 & 6,0 \\
\hline & Especialização ou MBA & 201 & 11,0 \\
\hline & Mestrado & 110 & 6,0 \\
\hline & Doutorado & 18 & 1,0 \\
\hline & Pós-doutorado & 5 & 0,3 \\
\hline \multirow{6}{*}{ Raça } & Branca & 1.210 & 66,1 \\
\hline & Negra & 176 & 9,6 \\
\hline & Amarela ou oriental & 18 & 1,0 \\
\hline & Parda & 417 & 22,8 \\
\hline & Indígena & 7 & 0,4 \\
\hline & Outra & 2 & 0,1 \\
\hline \multirow{7}{*}{ Ascendência } & Brasileira & 1.219 & 68,4 \\
\hline & Alemã & 125 & 7,0 \\
\hline & Italiana & 240 & 13,5 \\
\hline & Japonesa & 4 & 0,2 \\
\hline & Portuguesa & 68 & 3,8 \\
\hline & Não sei & 56 & 3,1 \\
\hline & Outra & 70 & 4,0 \\
\hline \multirow{15}{*}{ Renda mensal } & Funcionário (a) público (a) & 390 & 21,6 \\
\hline & Autônomo (a) & 177 & 9,8 \\
\hline & Profissional liberal & 61 & 3,3 \\
\hline & Empregado (a) assalariado (a) & 585 & 32,3 \\
\hline & Agricultor (a) & 15 & 0,8 \\
\hline & Aposentado (a) & 50 & 2,8 \\
\hline & Não trabalha & 301 & 16,7 \\
\hline & Outro & 229 & 12,7 \\
\hline & $\begin{array}{l}\text { Até } 1 \text { salário mínimo } \\
\text { Mais de } 1 \text { até } 2 \text { salários }\end{array}$ & 254 & 14,9 \\
\hline & mínimos & 529 & 31,0 \\
\hline & Mais de 2 a 3 salários mínimos & 356 & 20,9 \\
\hline & $\begin{array}{c}\text { Mais de } 3 \text { a } 5 \text { salários mínimos } \\
\text { Mais de } 5 \text { a } 10 \text { salários }\end{array}$ & 194 & 11,4 \\
\hline & $\begin{array}{l}\text { mínimos } \\
\text { Mais de } 10 \text { a } 20 \text { salários }\end{array}$ & 262 & 15,4 \\
\hline & $\begin{array}{c}\text { mínimos } \\
\text { A cimérimase }\end{array}$ & 93 & 5,5 \\
\hline & & 15 & 0,9 \\
\hline
\end{tabular}

Fonte: Elaborado pelos autores (2014). 
Outro questionamento realizado referiu-se ao grau de escolaridade do participante, na medida em que o mesmo pode influenciar no nível de alfabetização financeira e, por consequência, no endividamento com cartão de crédito. Pelos resultados, verificou-se que a maioria dos indivíduos apresenta um bom nível de instrução educacional, uma vez que $51 \%$ estão cursando ou já concluíram um curso técnico ou curso de graduação e $17 \%$ estão cursando ou já concluíram um curso de especialização/MBA ou pós-graduação.

Quanto às variáveis raça e ascendência, a amostra caracterizou-se por ser, predominantemente, branca (66,1\%) e de origem brasileira (68,4\%). Além desse perfil, merecem destaque os respondentes de raça parda $(22,8 \%)$ e ascendência italiana (13,5\%), os quais se caracterizaram como os de segunda maior representatividade. No que tange à ocupação, os respondentes, distribuíram-se entre empregado assalariado (32,3\%), funcionário público $(21,6 \%)$ e autônomo (9,8\%). Em relação ao rendimento, a maior parcela dos respondentes $(66,8 \%)$ recebe mensalmente até 3 salários mínimos. Mais especificamente, 14,9\% recebem até um salário mínimo, 31\% ganham entre um e dois salários e 20,9\% auferem entre dois e três salários mínimos. Importante ainda destacar, que significativa parcela dos respondentes $(15,4 \%)$ tem um bom rendimento mensal - entre 5 e 10 salários mínimos - o que contribuiu para elevar a média salarial, a qual correspondeu a $R \$ 2.450,00$.

Concluída a análise do perfil da amostra, partiu-se para a avaliação dos aspectos referentes ao uso do cartão de crédito. Em relação ao número de cartões de crédito apresentados pelos respondentes, a maior parcela relatou possuir somente um $(46,9 \%)$ ou dois cartões de crédito $(32,6 \%)$. No que se refere ao número de cartões efetivamente utilizados, novamente, a maior parte dos respondentes concentra os gastos em um $(61,4 \%)$ ou dois $(28,2 \%)$ cartões de crédito. Apesar de uma parcela significativa $(20,4 \%)$ possuir 3 ou mais cartões, somente 10,4\% costuma utilizá-los ativamente. Porcentagem semelhante foi encontrada por Norvilitis e MacLean (2010). Em pesquisa realizada com 173 estudantes, os autores observaram que 39,3\% possuem 1 único cartão, 16,2\% possuem 2 cartões e 15\% dos estudantes apresentam 3 ou mais cartões. Segundo Kim e DeVaney (2001), a posse de um maior número de cartões contribui para a elevação do endividamento, tendo em vista que indivíduos detentores de um maior número de cartões possuem uma fonte de crédito (empréstimo) muito superior àqueles que detêm um menor número de cartões. A Tabela 2 apresenta os resultados.

Tabela 2 . Aspectos relacionados ao cartão de crédito no que se refere ao número de cartões possuídos e utilizados, conhecimento da taxa de juros, valor do limite do cartão de crédito, percentual da renda e valor aproximado do gasto mensal no cartão de crédito

\begin{tabular}{|c|c|c|c|}
\hline Variável & Alternativas & Frequência & Percentual \\
\hline \multirow{4}{*}{ Número de cartões de crédito } & 1 & 859 & 46,9 \\
\hline & 2 & 597 & 32,6 \\
\hline & 3 & 213 & 11,6 \\
\hline & 4 ou mais & 162 & 8,8 \\
\hline \multirow{3}{*}{ Quantos cartões de crédito são utilizados de forma ativa? } & & 1.124 & 61,4 \\
\hline & 2 & 516 & 28,2 \\
\hline & 3 & 119 & 6,5 \\
\hline \multirow{2}{*}{$\begin{array}{l}\text { Se a taxa de juros do cartão de crédito for muito elevada, você } \\
\text { continua utilizando o cartão da mesma forma do que se a taxa for } \\
\text { menor? }\end{array}$} & Nัก & 1207 & 668 \\
\hline & Sim & 599 & 33,2 \\
\hline \multirow{2}{*}{$\begin{array}{l}\text { Você conhece o valor da taxa de juros do cartão de crédito } \\
\text { utilizado com maior frequência? }\end{array}$} & Não & 1.346 & 73,6 \\
\hline & Sim & 485 & 26,4 \\
\hline \multirow{6}{*}{ Valor do maior limite do cartão de crédito } & $\mathrm{R} \$ 0,00$ a $\mathrm{R} \$ 250,00$ & 111 & 6,4 \\
\hline & $\mathrm{R} \$ 251,00$ a $\mathrm{R} \$ 500,00$ & 264 & 15,2 \\
\hline & $\mathrm{R} \$ 501,00$ a $\mathrm{R} \$ 1.000,00$ & 391 & 22,6 \\
\hline & $\mathrm{R} \$ 1.001,00$ a $\mathrm{R} \$ 2.500,00$ & 383 & 22,1 \\
\hline & $\mathrm{R} \$ 2.501,00$ a $\mathrm{R} \$ 5.000,00$ & 295 & 17,0 \\
\hline & $\mathrm{R} \$ 5.001,00$ a $\mathrm{R} \$ 10.000,00$ & 169 & 9,7 \\
\hline
\end{tabular}




\begin{tabular}{|c|c|c|c|}
\hline Variável & Alternativas & Frequência & Percentual \\
\hline \multirow{2}{*}{$\begin{array}{l}\text { Percentual da renda mensal gasto com o pagamento do cartão de } \\
\text { crédito }\end{array}$} & $\begin{array}{l}0 \% \text { a } 30 \% \\
31 \% \text { a } 60 \%\end{array}$ & $\begin{array}{l}1.115 \\
415\end{array}$ & $\begin{array}{c}67 \\
24,9\end{array}$ \\
\hline & $61 \%$ a $100 \%$ & 136 & 8,1 \\
\hline \multirow{5}{*}{ Valor aproximado do gasto mensal com cartão de crédito } & $\begin{array}{c}\mathrm{R} \$ 0,00 \text { a } \mathrm{R} \$ 250,00 \\
\mathrm{R} \$ 251,00 \text { a } \mathrm{R} \$ 500,00\end{array}$ & $\begin{array}{l}585 \\
508\end{array}$ & $\begin{array}{l}33,8 \\
29,4\end{array}$ \\
\hline & $\mathrm{R} \$ 501,00$ a $\mathrm{R} \$ 1.000,00$ & 335 & 19,4 \\
\hline & $\mathrm{R} \$ 1.001,00$ a $\mathrm{R} \$ 2.500,00$ & 221 & 12,8 \\
\hline & $\mathrm{R} \$ 2.501,00$ a $\mathrm{R} \$ 5.000,00$ & 64 & 3,7 \\
\hline & Acima de $\mathrm{R} \$ 5.000,00$ & 15 & 0,9 \\
\hline
\end{tabular}

Fonte: Elaborado pelos autores (2014).

Quando questionados acerca da continuidade de utilização do cartão de crédito, caso a taxa de juros incidente sofresse uma elevação, 66,8\% declararam que diminuiriam a frequência de uso. Apesar desse indicativo de prudência, somente $26,4 \%$ dos respondentes declararam conhecer o valor da taxa mensal de juros incidente sobre a dívida do cartão (valor da fatura integral não quitado). Esses dados confirmam o resultado obtido por uma pesquisa realizada em 2013 pelo Serviço de Proteção ao Crédito (SPC) com objetivo de mapear os hábitos e comportamentos mais comuns do brasileiro na hora de utilizar as opções de crédito. Tendo por base um levantamento realizado com 604 pessoas de todas as capitais brasileiras, concluiu-se que $72 \%$ dos usuários não sabem quanto pagam pelos juros no crédito rotativo quando deixam de quitar o valor integral da fatura. $\mathrm{O}$ estudo mostra ainda que o brasileiro demonstra interesse em saber o quanto vai desembolsar para adquirir o cartão (79\% conhece o valor da anuidade), mas ignora o valor dos custos secundários como a multa paga por atrasar o pagamento. Tal resultado torna-se preocupante, na medida em que o desconhecimento do valor da taxa de juros atrelado ao descontrole nos gastos pode aumentar a propensão ao endividamento, ainda mais se considerado o valor exorbitante das taxas de juros do crédito rotativo, as quais podem alcançar 200\% ao ano no Brasil (SPC, 2013).

O estudo realizado por Warwick e Mansfield (2000) confirma o desconhecimento acerca do valor da taxa de juros. Em pesquisa realizada com 378 estudantes de graduação, os autores constataram que $71 \%$ não tem ideia sobre o valor da taxa de juros paga em caso de uso do crédito rotativo do cartão. Os autores ainda observaram que os estudantes detêm um conhecimento mais apurado do valor do limite de crédito disponível (57\% sabem o valor do limite) e do valor do saldo devedor do cartão (52,5\% sabem o quanto estão devendo no cartão), se contrastados com o nível de conhecimento da taxa de juros.

$\mathrm{Na}$ sequência, questionaram-se os respondentes acerca do valor do limite do cartão de crédito, obtendo-se a seguinte distribuição: 44,3\% possuem limite inferior a $\mathrm{R} \$ 1.000,00,39 \%$ entre $\mathrm{R} \$ 1.001,00$ e $\mathrm{R} \$ 5.000,00$ e $16,6 \%$ possuem limite superior a $R \$ 5.001,00$. Se considerado o nível médio de renda ( $\mathrm{R} \$ 2.450,00)$, parcela representativa dos respondentes $(55,7 \%)$ apresenta níveis elevados de limite de crédito (superior a $\mathrm{R} \$ 2.500,00$ ).

Em relação ao percentual da renda mensal destinada ao pagamento da fatura do cartão de crédito, em média, os respondentes utilizam 30\% do rendimento com um desvio padrão de $20,5 \%$, indicando que os gastos concentram-se, principalmente, na faixa entre $10 \%$ e $50 \%$. Resultado semelhante foi obtido por Norvilitis e MacLean (2010) que verificaram que os estudantes americanos costumam gastar, em média, 18\% de sua renda mensal com o cartão de crédito. Considerando que gastar mais de 30\% da renda mensal com o pagamento do cartão, aumenta a propensão do indivíduo em ter dificuldades para pagar integralmente suas contas (LYONS, 2004), os participantes da pesquisa mostraram-se cautelosos e coerentes no uso do crédito, uma vez que expressiva porcentagem (67\%) costuma gastar menos de 30\% do salário com esse instrumento de crédito.

O resultado obtido no questionamento quanto ao valor gasto mensalmente no cartão de crédito, corrobora o resultado auferido na questão anterior. Parcela significativa dos respondentes $(63,2 \%)$ costuma gastar menos de $\mathrm{R} \$ 500,00$ mensais no cartão de crédito. Somente $17,4 \%$ realizam compras em valor superior a $\mathrm{R} \$ 1.001,00$ por 
mês. Entre as possíveis explicações para o baixo valor gasto destacam-se o bom senso e o controle financeiro mantido pelos respondentes ou ainda o baixo valor do limite de crédito apresentado por parcela considerável dos respondentes $(44,2 \%$ possuem limite de crédito inferior a $\mathrm{R} \$ 1.000,00)$.

Segundo Norvilitis e MacLean (2010), os indivíduos tendem a usar o cartão de crédito como um instrumento para melhorar seu bem-estar, reduzir a ansiedade e ser reconhecido no grupo social. Tal fato é confirmado nesse estudo, ao se observar que, em média, os indivíduos costumam utilizar, mais frequentemente, o cartão de crédito para a aquisição de roupas $(30,4 \%)$ e presentes $(7,9 \%)$ e, para custear gastos em restaurantes $(7,5 \%)$ e boates/ cinemas $(7,7 \%)$, gastos esses voltados, principalmente, ao bem-estar e à satisfação pessoal. Segundo estudo promovido pela ABECS (2013), os indivíduos costumam utilizar o cartão de crédito, mais frequentemente, para a aquisição de bens duráveis para a casa (50\%), compra de passagens (49\%), estada em hotéis e pousadas (41\%), vestuário e acessórios (33\%), farmácia e cosméticos (24\%), alimentos (23\%), postos de combustível $(22 \%)$ restaurantes $(16 \%)$, lazer $(9 \%)$ e educação $(6 \%)$.

Após conhecer o perfil dos respondentes, em termos de variáveis demográficas e econômicas, e conhecer alguns aspectos relacionados ao uso do cartão de crédito, buscou-se analisar o endividamento no cartão de crédito. Para tanto, foi utilizada uma escala desenvolvida com base nas questões propostas por Wang, Lu e Malhotra (2011). Oferecendo cinco possibilidades de resposta (discordo totalmente, discordo, indiferente, concordo e concordo totalmente), a escala buscou avaliar a propensão de o indivíduo tornar-se inadimplente no cartão, assim como as dificuldades em quitar a fatura. A Tabela 3 elenca as questões componentes do fator e a estatística descritiva resultante das análises.

Tabela 3 . Estatística descritiva para o fator Dívida no cartão de crédito

\begin{tabular}{l|c|c|c}
\hline \multicolumn{1}{c}{ Variáveis } & \multicolumn{1}{c}{ Média } & \multicolumn{1}{c}{ Mediana } & \multicolumn{1}{c}{ Desvio padrão } \\
\hline Opto por parcelar o pagamento dos produtos adquiridos com cartão de crédito. & 3,070 & 3,000 & \multicolumn{1}{c}{1,094} \\
\hline Dependo do cartão de crédito para pagar despesas corriqueiras. & 2,010 & 2,000 & 1,093 \\
\hline Nos últimos 12 meses, deixei de pagar a fatura integral do cartão de crédito. & 1,530 & 1,000 & 0,945 \\
\hline Nos últimos 12 meses, paguei somente a fatura mínima exigida & 1,500 & 1,000 & 0,960 \\
\hline Nos últimos 12 meses, recorri ao saque disponível no cartão de crédito. & 1,460 & 1,000 & 0,890 \\
\hline Nos últimos 12 meses, estourei o limite do cartão de crédito. & 1,510 & 1,000 & 0,967 \\
\hline
\end{tabular}

Fonte: Elaborado pelos autores (2014).

Através da análise da Tabela 3, verifica-se que os indivíduos são responsáveis na hora de utilizar o cartão de crédito, uma vez que a maior parcela raramente ou nunca deixou de pagar o valor integral da fatura (média 1,53), recorreu ao saque do cartão (média 1,46) ou ultrapassou o limite disponível (média 1,51) considerando o período dos últimos doze meses. Importante também destacar, que parcela considerável dos respondentes (70,3\%) não depende do cartão para pagar despesas corriqueiras. No entanto, apesar de não muito elevada, percebe-se que a média mais alta foi atribuída a questão: "Opto por parcelar o pagamento dos produtos adquiridos com cartão de crédito" (média 3,07), demonstrando que a compra através de um cartão de crédito faz com que o indivíduo prefira comprar a prazo do que à vista, comprometendo a saúde financeira por mais tempo.

Resultados semelhantes foram encontrados por Shefrin e Nicols (2014). Os autores desenvolveram duas pesquisas survey, uma em maio de 2009 com um público de 1.047 norte-americanos e outra em junho de 2009 com a participação de 4.026 norte-americanos. O objetivo do estudo era explicar quais eram as características e padrões de comportamento dos portadores de cartão de crédito, principalmente levando em conta aspectos como objetivos financeiros, espontaneidade do comportamento de compra, controle dos impulsos e confiança demonstrada na gestão das finanças pessoais e domésticas. No geral, os autores observaram que os indivíduos pesquisados costumam pagar sempre ou frequentemente o valor integral da fatura e, ainda, utilizam o cartão 
somente para despesas emergenciais ou a realização de grandes compras.

Em seguida, objetivando verificar as relações estabelecidas entre as variáveis estudadas e a propensão à dívida no cartão de crédito, aplicaram-se os testes de diferença de média (teste $t$ ) e análise de variância (ANOVA). Para averiguar as diferenças de média entre dois grupos foi utilizado o teste $t$ de Student, o qual compara a média de uma variável em um grupo com a média da mesma variável em outro grupo. A fim de determinar se o teste $t$ é homocedástico ou heterocedástico aplicou-se o teste de igualdade de variâncias, conforme Pestana e Gageiro (2008). Já para variáveis com mais de dois grupos aplicou-se a análise de variância (ANOVA), a qual permite comparar, simultaneamente, a média de vários grupos utilizando variáveis contínuas.

Para a formação dos grupos a serem testados foram consideradas quinzes variáveis: gênero, idade, estado civil, dependentes, filhos, nível de escolaridade, raça, ascendência, ocupação, renda, número de cartões, conhecimento da taxa de juros, valor do limite do cartão de crédito, percentual da renda e valor aproximado do gasto mensal no cartão de crédito.

A variável idade foi transformada em uma variável ordinal sendo o grupo 1 formado por indivíduos com as menores idades (até 22 anos), o grupo 2 por indivíduos com idade entre 23 e 27 anos, o grupo 3 por aqueles entre 28 e 36 anos e, o último grupo é formado pelos indivíduos com mais de 36 anos. A variável renda, por sua vez, foi organizada em 6 grupos de acordo com o número de salários mínimos recebidos $^{2}$ (grupo 1 = até 1 salário mínimo; grupo 2 = mais de 1 até 2 salários; grupo $3=$ mais de 2 até 3 salários; grupo $4=$ mais de 3 até 5 salários; grupo 5 $=$ mais de 5 salários; grupo $6=$ acima de 10 salários mínimos).

A variável número de cartões de crédito foi organizada em 4 grupos, sendo considerado para essa divisão o número de cartões possuídos (grupo $1=1$ cartão; grupo $2=2$ cartões; grupo $3=3$ cartões; grupo 4 $=4$ ou mais cartões de crédito). $\mathrm{O}$ valor do limite no cartão de crédito foi dividido em 7 grupos, conforme segue: grupo $1=$ limite entre $\mathrm{R} \$ 0,00$ e $\mathrm{R} \$ 250,00$; grupo $2=R \$ 251,00$ a $R \$ 500,00$; grupo $3=R \$$ 501,00 a $\mathrm{R} \$ 1.000,00$; grupo $4=\mathrm{R} \$ 1.001,00$ a $\mathrm{R} \$$ 2.500,00; grupo $5=\mathrm{R} \$ 2.501,00$ a $\mathrm{R} \$ 5.000,00$; grupo $6=\mathrm{R} \$ 5.001,00$ a $\mathrm{R} \$ 10.000,00$ e grupo $7=$ limite acima de $R$ \$ 10.001,00. A variável percentual da renda mensal gasta com cartão de crédito foi organizada em 3 grupos (grupo $1=0 \%$ a 30\% da renda; grupo $2=$ $31 \%$ a $60 \%$ e, grupo $3=61 \%$ a $100 \%$ da renda) e, por fim, a variável valor do gasto mensal com cartão de crédito, organizada em 5 grupos (grupo $1=\mathrm{R} \$ 0,00$ a $\mathrm{R} \$ 250,00$; grupo $2=\mathrm{R} \$ 251,00$ a $\mathrm{R} \$ 500,00$; grupo $3=\mathrm{R} \$ 501,00$ a $\mathrm{R} \$ 1.000,00$; grupo $4=\mathrm{R} \$ 1.001,00$ a $\mathrm{R} \$ 2.500,00$ e grupo $5=$ acima de $\mathrm{R} \$ 2.501,00)$. As Tabelas 4 e 5 apresentam os resultados do teste $t$ e ANOVA, respectivamente.

Tabela 4 . Teste t para o construto Propensão à dívida no uso do cartão de crédito

\begin{tabular}{|c|c|c|c|}
\hline \multirow{2}{*}{ Fator } & \multirow{2}{*}{ Variáveis } & \multicolumn{2}{|c|}{ Teste $\mathbf{t}$} \\
\hline & & Valor & Sig. \\
\hline \multirow{4}{*}{$\begin{array}{l}\text { Propensão } \\
\text { à dívida } \\
\text { no uso do } \\
\text { cartão de } \\
\text { crédito }\end{array}$} & Gênero & 1819,000 & 0,617 \\
\hline & Dependentes & 831.546 & 0,000 \\
\hline & Filhos & 1070,123 & 0,000 \\
\hline & $\begin{array}{l}\text { Conhecimento } \\
\text { da taxa de juros }\end{array}$ & 1826,000 & 0,087 \\
\hline
\end{tabular}

Fonte: Elaborado pelos autores (2014).

Ao analisar os resultados obtidos no teste $t$, observa-se que apenas as variáveis dependentes e filhos apresentaram diferenças significativas. Nesse sentido, verifica-se que os indivíduos que possuem dependentes (média 1,95), assim como os que possuem filhos (média 1,93), são os que apresentam maiores médias, ou seja, o tamanho do agregado familiar está positivamente relacionado com o endividamento no cartão de crédito. Esses resultados corroboram os achados de Bertaut e Haliassos (2005), pois ao realizar um estudo junto à população norteamericana, os autores verificaram que familias com mais de duas crianças tendem a apresentar maior nível de endividamento no cartão de crédito. 
Tabela 5 . ANOVA para o construto Propensão à dívida no uso do cartão de crédito

\begin{tabular}{|c|c|c|c|}
\hline \multirow{2}{*}{ Fator } & \multirow{2}{*}{ Variáveis } & \multicolumn{2}{|c|}{ ANOVA } \\
\hline & & Valor & Sig. \\
\hline \multirow{11}{*}{$\begin{array}{l}\text { Propensão à dívida no uso do } \\
\text { cartão de crédito }\end{array}$} & Idade & 1,942 & 0,121 \\
\hline & Estado civil & 1,002 & 0,367 \\
\hline & Escolaridade & 2,881 & 0,013 \\
\hline & Raça & 8,606 & 0,000 \\
\hline & Ascendência & 7,185 & 0,000 \\
\hline & Ocupação & 1,157 & 0,327 \\
\hline & Renda & 1,732 & 0,124 \\
\hline & Número de cartões de crédito & 11,728 & 0,000 \\
\hline & Limite do cartão de crédito & 0,685 & 0,662 \\
\hline & Percentual da renda gasta com cartão de crédito & 64,419 & 0,000 \\
\hline & Valor aproximado do gasto mensal no cartão de crédito & 10,721 & 0,000 \\
\hline
\end{tabular}

Fonte: Elaborado pelos autores (2014).

Com relação ao teste ANOVA, mostraram-se significativas as diferenças de média para as variáveis: escolaridade, raça, ascendência, número de cartões de crédito, percentual da renda gasta com cartão de crédito e valor aproximado do gasto mensal no cartão de crédito. Ao avaliar a variável escolaridade, observou-se que os indivíduos com menor grau de escolaridade (média 2,00) tendem a ser mais endividados que aqueles com maior instrução educacional. Nesse sentido, Davies e Lea (1995) argumentam que indivíduos de baixa renda costumam endividar-se mais no cartão de crédito em razão da necessidade de recursos financeiros para quitar compromissos ou, ainda, pelo fato de o aumento de renda não ser suficiente para acompanhar o aumento das despesas, fazendo com que os mesmos continuem dispostos a usar o crédito rotativo para atender as demandas.

Investigando a variável raça, Lyons (2004) verificou que os grupos étnicos minoritários são mais propensos a utilizar o crédito rotativo do cartão de crédito, confirmando os resultados encontrados neste estudo, tendo em vista que os indivíduos pertencentes a categoria "outra" (média 2,09) foram os que apresentaram maiores médias, se comparados com os brancos, negros e pardos. Quanto a variável ascendência, encontrou-se uma maior propensão dos portugueses (média 1,98), do que das outras ascendências, a contraírem dívidas no cartão de crédito. Em seguida, ficaram os indivíduos que se disseram de outra ascendência (média 1,97), com destaque para os espanhóis.

Iniciando a análise das variáveis utilizadas para mensurar características do cartão de crédito, notou-se que indivíduos que possuem 3 cartões (média 2,01) e 4 ou mais cartões (média 1,96) são mais propensos à dívida que aqueles que possuem 1 (média 1,77) ou 2 cartões de crédito (média 1,88). Esse resultado suporta os achados de Norvilitis et al. (2006) e Wang, Lu e Malhotra (2011), ratificando a relação positiva entre número de cartões e dívida no cartão de crédito. Segundo Kim e DeVaney (2001), o número de cartões de crédito desempenha um importante papel no aumento do nível de dívida, uma vez que indivíduos detentores de um maior número de cartões possuem uma fonte de crédito superior àqueles que detêm menor número de cartões.

Por fim, averiguaram-se as variáveis percentual da renda e valor do gasto mensal no cartão de crédito, sendo descoberto que os indivíduos que costumam gastar uma parcela significativa da sua renda (61\% a 100\% (média $2,25)$ ) apresentam maiores níveis de dívida que aqueles que gastam valores inferiores. Da mesma forma, observouse que os indivíduos que gastam entre $\mathrm{R} \$ 1.001,00$ e $\mathrm{R} \$ 2.500,00$ (média 1,96) também demonstraram-se mais propensos a níveis elevados de dívida no cartão de crédito. Esse resultado corrobora os pressupostos da literatura que apontam para a existência de uma relação positiva entre valor do gasto e dívida no cartão de crédito.

Em seguida, com o intuito de verificar a influência das variáveis analisadas na propensão à dívida no uso do cartão de crédito, realizou-se a regressão linear múltipla. Para tanto, foi considerado o fator Dívida no cartão 
de crédito como dependente e como independente foram elencadas as variáveis: percentual de renda mensal gasto com o pagamento do cartão de crédito; valor aproximado do gasto mensal em todos os cartões de crédito; valor aproximado da dívida atual no cartão de crédito, devido ao não pagamento da fatura integral; limite nos cartões de crédito; renda mensal líquida aproximada; dummy de gênero, de dependentes, de escolaridade, de estado civil e de ocupação.

Para a estimação do modelo de regressão linear, utilizou-se a estimação por Mínimos Quadrados Ordinários (MQO) e método Stepwise. Na primeira tentativa de estimação observou-se que os erros eram heterocedásticos. Para resolver este problema utilizou-se a técnica White Heteroskedasticity-Consistent Standart Erros \& Covariance, a qual corrige os erros-padrões e convariâncias, tornando-os consistentes com o pressuposto de não-heterocedasticidade. O modelo estimado é descrito na Tabela 6.

Tabela 6 - Resultados da regressão múltipla por Mínimos Quadrados Ordinários pelo método Stepwise, estimada para o comportamento da dívida no uso do cartão de crédito.

\begin{tabular}{|c|c|c|c|c|}
\hline \multirow{2}{*}{ Variáveis } & \multirow{2}{*}{ Coeficientes não padronizados } & \multicolumn{2}{|c|}{ Teste $\mathrm{t}$} & \multirow{2}{*}{ VIF } \\
\hline & & Valor & Sig. & \\
\hline Constante & 0,4925 & 5,1178 & 0,0000 & - \\
\hline Dummy de dependentes & 0,0588 & 1,8537 & 0,0645 & 1,0801 \\
\hline \multirow{2}{*}{ Variáveis } & \multirow{2}{*}{ Coeficientes não padronizados } & \multicolumn{2}{|c|}{ Teste $\mathrm{t}$} & \multirow{2}{*}{ VIF } \\
\hline & & Valor & Sig. & \\
\hline $\begin{array}{l}\text { Quanto você possui de limite no(s) seu(s) cartão(ões) de } \\
\text { crédito? }\end{array}$ & $-0,0748$ & $-4,5924$ & 0,0000 & 1,8657 \\
\hline $\begin{array}{l}\text { Qual o valor aproximado de sua dívida atual no cartão de } \\
\text { crédito, devido ao não pagamento da fatura integral? }\end{array}$ & 0,0785 & 5,1310 & 0,0000 & 1,9354 \\
\hline $\begin{array}{l}\text { Qual o percentual de sua renda mensal é gasto com o } \\
\text { pagamento do(s) seu(s) cartão(ões) de crédito? }\end{array}$ & 0,0855 & 4,6101 & 0,0000 & 1,0846 \\
\hline
\end{tabular}

Fonte: Elaborado pelos autores (2014).

O resultado apresenta quatro variáveis independentes, com um R2 ajustado de 0,17 , o que significa que as variáveis independentes em conjunto explicam $17 \%$ da variável dependente. A significância do teste $\mathrm{F}$ (valor 21,444 e sig. 0,0000 ) indica que pelo menos uma das variáveis independentes exerce influência sobre a variável dependente, sendo considerado o modelo significativo.

Quanto aos pressupostos do modelo, observou-se que: (i) não há autocorrelação serial, uma vez que o valor do teste de Durbin Watson $(1,77)$ ficou próximo de 2; (ii) o modelo não apresenta problemas de multicolinearidade, dado que os FIVs ficaram próximos a 1; e (iii) os resíduos do modelo possuem distribuição normal, uma vez que o teste Kolmogorov-Smirnov não foi significativo (0,570 e sig. 0,902).

Após a conclusão dos testes pode-se afirmar que o modelo de regressão está adequado. Assim, analisando os coeficientes, que expressam a magnitude e a direção da relação de cada uma das variáveis independentes sobre a variável dependente, constatou-se que a variável "Quanto você possui de limite no(s) seu(s) cartão(ões) de crédito?” exerce influência negativa. Dessa forma, indivíduos com altos limites são menos propensos a dívida, ou seja, conseguem pagar a fatura integral do cartão de crédito. Pode-se conjecturar que este resultado também esteja associado ao fato de que as operadoras de cartão de crédito geralmente concedem limites elevados a detentores de maiores rendas.

Já as variáveis "Qual o valor aproximado de sua dívida atual no cartão de crédito, devido ao não pagamento da fatura integral?" e "Qual o percentual de sua renda mensal é gasto com o pagamento do(s) seu(s) cartão(ões) 
de crédito?" exibem coeficientes positivos, indicando uma relação direta, ou seja, quanto maior o valor da dívida atual no cartão e quanto maior o percentual da renda gasta com o pagamento do cartão, maior será a propensão à dívida no cartão de crédito.

Confirmam-se assim, as evidências destacadas anteriormente por Moreira (2000), por exemplo, o qual afirma que quanto maior for o nível de gastos, maior será a probabilidade de contrair dívidas, sendo que o indivíduo que mantém o nível de gastos descontrolado por um longo período, poderá obter níveis significativos de dívida.

Quanto ao fato de possuírem ou não dependentes, o coeficiente revelou-se positivo, indicando que os indivíduos que possuem dependentes exibem níveis mais elevados de propensão à dívida no cartão de crédito. Essa conclusão também é encontrada por Tan, Yen e Loke (2011), os quais verificaram que os indivíduos com dependentes e/ou filhos apresentam maior nível de dívida.

As demais variáveis (valor aproximado do gasto mensal em todos os cartões de crédito; renda mensal líquida aproximada; dummy de gênero, de escolaridade, de estado civil e de ocupação) não se mostraram significativas, ou seja, nessa amostra específica, elas não influenciam na propensão à dívida no cartão de crédito e, por esse motivo, não são apresentadas e foram retiradas do modelo.

\section{Considerações finais}

A indiscutível facilidade no acesso e na utilização do cartão de crédito, assim como a sua praticidade, pode acarretar na inserção de classes menos favorecidas no mercado consumidor, assim como o uso indiscriminado desse meio de pagamento pode levar à acumulação de dívidas, comprometendo a saúde financeira do indivíduo. Sendo assim, o objetivo principal deste estudo foi construir um indicador de comportamento de propensão à dívida no cartão de crédito, e o objetivo secundário foi avaliar a influência dos aspectos demográficos, culturais e das características do cartão de crédito na propensão à dívida no cartão.

A maior parte da amostra foi composta por respondentes do gênero feminino, com média de 31 anos de idade, solteiros, sem dependentes e/ou filhos e, ainda, estão cursando ou já concluíram um curso técnico ou de graduação. Além disso, a maioria dos respondentes são brancos, empregados assalariados e funcionários públicos, sendo que recebem até três salários mínimos.

Com relação aos aspectos referentes ao uso do cartão de crédito, a maior parte dos indivíduos possui somente um cartão, sendo que diminuiriam a frequência de uso caso a taxa de juros aumentasse. No entanto, um número baixo de respondentes declararam conhecer o valor da taxa mensal. Por fim, a maior parcela dos indivíduos possui um limite inferior a $\mathrm{R} \$ 1.000,00 \mathrm{e}$, ainda, gastam, em média, 30\% do rendimento com o pagamento da fatura do cartão.

Ao analisar a propensão à dívida no uso do cartão de crédito, verificou-se que os indivíduos sabem utilizar esse meio de pagamento de forma consciente, de forma que raramente deixaram de pagar o valor integral da fatura ou, ainda, recorreram ao saque do cartão e ultrapassaram o limite disponível. Assim, constata-se que os respondentes da pesquisa estão operando o cartão de crédito de forma responsável e estão sabendo aproveitar os benefícios desse meio de pagamento.

Por outro lado, o estudo demonstrou que variáveis demográficas e características de uso do cartão de crédito influenciam no nível de propensão à dívida no cartão. Os indivíduos com dependentes e/ou filhos, com baixa escolaridade, de outras raças e portugueses foram os que se demonstraram mais propensos à dívida no cartão de crédito. Além disso, aqueles que possuem 3 cartões, que costumam gastar uma parcela significa da renda e aqueles que gastam entre $\mathrm{R} \$ 1.001,00$ e $\mathrm{R} \$ 2.500,00$ também manifestaram-se como mais propensos a esse comportamento.

Notou-se também que a propensão à dívida no uso do cartão de crédito pode ser influenciada por questões como: dependentes, valor aproximado da dívida atual no cartão e percentual da renda gasta com o pagamento do mesmo, sendo que essas variáveis exercem influência positiva no construto investigado. O limite no cartão de crédito, no entanto, exerce influência negativa na propensão à dívida no cartão de crédito.

Assim, tendo em vista o complexo cenário de recessão econômica em que o Brasil se encontra, o uso do parcelamento no cartão tende a se elevar, podendo ser 
mais um agravante da inadimplência. Um exemplo disso é que apenas no primeiro trimestre de 2015 o aumento no uso do cartão de crédito já havia subido 7,5\% em relação ao ano anterior (ABECS, 2015). Nesse sentido, o conhecimento acerca da atual situação do crédito torna-se de suma importância para as famílias e para a economia, considerando que o endividamento pode causar tanto problemas de ordem comportamental e psicológica para o devedor e a família quanto pode afetar o crescimento econômico do país.

Como uma das principais contribuições do estudo, destaca-se o reconhecimento das variáveis associadas à dívida para auxiliar na construção de modelos de concessão de crédito mais realistas e fidedignos, contribuindo, consequentemente, na prevenção e redução dos níveis de endividamento no cartão de crédito. A pesquisa também torna-se importante para o sistema bancário, uma vez que alguns bancos utilizam apenas variáveis demográficas no momento de analisar os titulares de cartão de crédito, assim como para determinar os limites de crédito. Além disso, instituições financeiras, administradores, organizações de proteção e defesa do consumidor, educadores, assim como a própria família, devem ajudar na conscientização dos usuários quanto a comportamentos responsáveis no uso do cartão de crédito, evidenciando as vantagens do cartão, mas também alertando quanto aos riscos no mau gerenciamento. Sugere-se também a criação de programas educacionais com o objetivo de orientar os indivíduos a adotar práticas orçamentárias como a definição de metas e o desenvolvimento de um plano de gastos, tendo em vista que os indivíduos que sabem aproveitar os benefícios do cartão de crédito, assim como o utilizam de forma equilibrada, sem ultrapassar os limites do orçamento, são menos propensos à dívida no cartão de crédito.

Por fim, como limitações do estudo tem-se a não generalização da amostra, tendo em vista que apesar de representativa, necessita ser ampliada, de forma a oferecer resultados mais completos. Além disso, quanto à técnica de coleta de dados, a pesquisa survey baseada em um questionário estruturado, abre espaço para a omissão de dados, podendo originar desvios no resultado do estudo. Para trabalhos futuros, sugere-se a reaplicação do estudo em outras amostras, juntamente com outras técnicas de coleta e análise dos dados, possibilitando o aprofundamento do conhecimento sobre o assunto.

\section{Agradecimentos}

Os autores agradecem ao Conselho Nacional de Desenvolvimento Científico e Tecnológico - CNPq pelo apoio financeiro.

\section{Notas}

${ }^{1}$ Segundo dados do censo demográfico realizado no ano de 2010 pelo Instituto Brasileiro de Geografia e Estatística (IBGE), a população brasileira é constituída por 190.755.799 milhões de habitantes.

${ }^{2}$ Considerou-se o valor de $\mathrm{R} \$$ 678,00 para o salário mínimo.

\section{Referências Bỉbliográficas}

\section{ASSOCIAÇÃO BRASILEIRA DAS EMPRESAS DE CARTÃO DE CRÉDITO E SERVIÇOS (ABECS). Mercado de cartões consolidado,} 2012. Disponível em: <http://www.abecs.org.br/ site2012/admin/arquivos/estudos/\%7B3A5E429CABC1-4EB1-B7DE-EEFF0D493342\%7D_2247-AMercadoDeCartoesConsolidado.pdf $>$. Acesso em: 16 jun. 2014.

\section{ASSOCIAÇÃO BRASILEIRA DAS \\ EMPRESAS DE CARTÃO DE CRÉDITO E} SERVIÇOS. Mercado de meios eletrônicos de pagamento. Disponível em: $<$ http://www. abecs.org.br/app/webroot/files/media/7/6/0/ b22af92330e3c5e830f69bee3e064.pdf $>$. Acesso em: 05 fev. 2014.

\section{ASSOCIAÇÃO BRASILEIRA DAS EMPRESAS DE CARTÃO DE CRÉDITO E SERVIÇOS.}

Indicadores do Mercado de Cartões, 2015. Disponível em: < http://www.abecs.org.br/ indicadores-de-mercado>. Acesso em: 03 set. 2015.

BAEK, E.; HONG, G. Effects of family life-cycle stages on consumer debts. Journal of Family and Economic Issues, v. 25, n. 3, p.359-385, 2004.

BERTAUT, C. C.; HALIASSOS, M. Credit cards: facts and theories. In: Social Science Research Network, 2005. Disponível em: < http://papers.ssrn. $\mathrm{com} / \mathrm{sol} 3 /$ papers.cfm?abstract id $=931179>$. Acesso em: 01 jun. 2014. 
CHIEN, Y.; DEVANEY, S. A. The effects of credit attitude and socioeconomic factors on credit card and installment debt. The Journal of Consumer Affairs, v. 35, n. 1, p. 162-179, 2001.

CONFEDERAÇÃO NACIONAL DO COMÉRCIO DE BENS, SERVIÇOS E TURISMO (CNC). Pesquisa Nacional de Endividamento e Inadimplência do Consumidor (PEIC) fevereiro 2014. Disponível em: < $\underline{\text { http: / / www.cnc. }}$ org.br/sites/default/files/arquivos/release peic fevereiro 2014.pdf>. Acesso em: 01 mar. 2014.

DAVIES, E.; LEA, S. E. G. Student attitudes to student debt. Journal of Economic Psychology, v. 16, n. 1, p. 663-679, 1995.

DISNEY, R.; GATHERGOOD, J. Financial literacy and indebtedness: new evidence for UK consumers. In: EconPapers, 2011. Disponível em: $<\underline{\text { http: } / /}$ econpapers.repec.org/paper/notnotcfc/112f05.

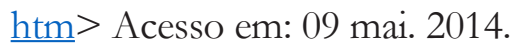

DURKIN, A. T. Credit cards: use and consumer attitudes. Federal Reserve Bulletin, v. 86, n. 9, p.623634, 2000.

GRABLE, J. E.; JOO, S. H. Student racial differences in credit card debt and financial behaviors and stress. College Student Journal, v. 40, n. 2, p. 400-408, 2006.

HAIR, J. R; BLACK, W. C.; BABIN, B. J.; ANDERSON, R. E. Multivariate Data Analyses. 7 Ed. New Jersey: Pearson, 2010.

\section{JOJI, A. N.; RAVEENDRAN, P. T. Compulsive} buying behavior in Indian consumers and its impact on credit default - an emerging paradigm, 2008. Disponível em: < http://dspace.iimk.ac.in/ bitstream/2259/329/1/545-562.pdf > . Acesso em: 03 jan. 2014.

KEESE, M. Who feels constrained by high debt burdens? - subjective vs. objective measures of household indebtedness. In: Social Science Research Network, 2010. Disponível em: $<$ http://papers.ssrn. $\mathrm{com} / \mathrm{sol} 3 /$ results.cfm?npage $=2 \&>$. Acesso em: 25 mai. 2014.

KEESE, M.; SCHMITZ, H. Broke, ill and obese: the effect of household debt on health. In: Social Science Research Network, 2010. Disponível em: < http://papers.ssrn.com/sol3/results. cfm?npage $=2 \&>$. Acesso em: 30 mai. 2014.

KIM, H.; DEVANEY, S. A. The determinants of outstanding balances among credit card revolvers, 2001. Association for Financial Counseling and Planning Education. Disponível em: < http://www. afcpe.org/assets/pdf/vol1216.pdf>. Acesso em: 17 jun. 2014.

KIM, H.; DEVANEY, S. A. The determinants of outstanding balances among credit card revolvers, 2001. Association for Financial Counseling and Planning Education. Disponível em: $<\underline{\text { http://www. }}$ afcpe.org/assets/pdf/vol1216.pdf > . Acesso em: 17 jun. 2014.

LEE, J.; HOGARTH, J. M. Returns to information search: Consumer credit card

shopping decision. Financial Counseling and Planning, v. 10 n. 2, p. 23-34, 1999.

LEE, J.; KWON, K. N. Consumers' use of credit cards: store credit card usage as an alternative payment and financing medium. Journal of Consumer Affairs, v. 36, n. 2, p. 239-262, 2002.

LIE, C.; HUNT, M.; PETERS, H. L.; VELIU, B.; HARPER, D. The 'negative' credit card effect: credit cards as spending-limiting stimuli in New Zealand. The Psychological Record, v. 60, n. 3, p. 339-412, 2010.

LYONS, A. C. A profile of financially at-risk college students. The Journal of Consumer Affairs, v. 38, n. 1, p. 56-80, 2004.

LYONS, A. C. Credit practices and financial education needs of Midwest college students. In: Social Science Research Network, 2007. Disponível em: < $\underline{\text { http:// }}$ www.acrwebsite.org/search/view-conferenceproceedings.aspx? Id=6915 > . Acesso em: 26 set. 2014.

MACGEE, J. The rise in consumer credit and bankruptcy: cause for concern? In: Social Science Research Network, 2012. Disponível em: < $\underline{\text { http:// }}$ papers.ssrn.com/sol3/papers.cfm? abstract_ id $=2046574>$. Acesso em: 17 jun. 2014.

MENDES-DA-SILVA, W. M.; NAKAMURA, W. T.; DE MORAES, D. C. Credit card risk behavior on college campuses: evidence from Brazil. Brazilian Administration Review, v. 9, n. 3, p. 351-373, 2012. 
MOREIRA, A. S. Valores e dinheiros: um estudo transcultural das relações entre prioridades de valores e significado do dinheiro para indivíduos. 228f. Tese (Doutorado em Psicologia) - Universidade de Brasília, Brasília, 2000.

NORUM, P. S. The role of time preference and credit card usage in compulsive buying behavior. International Journal of Consumer Studies, v. 32, n. 3, p. 269-275, 2008.

NORVILITIS, J. M.; et al. Personality factors, money attitudes, financial knowledge, and credit-card debt in college students. Journal of Applied Social Psychology, v. 36, n. 6, p. 1395-1413, 2006.

NORVILITIS, J. M.; SZABLICKI, P. B.; WILSON, S. D. Factors influencing levels of credit card debt in college students. Journal of Applied Social Psychology, v. 33, n. 5, p. 935-947, 2003.

NORVILITS, J. M.; MACLEAN, M. G. The role of parents in college students' financial behaviors and attitudes. Journal of Economic Psychology, v. 31, n. 1, p. 55-63, 2010.

PARK, H. J.; BURNS, L. D. Fashion orientation, credit card use, and compulsive buying. Journal of Consumer Marketing, v. 22, n. 3, p. 135-141, 2005.

PESTANA, M. H.; GAGEIRO, J. N. Análise de dados para ciências sociais: a complementaridade do SPSS. 5. Ed. Lisboa: Silabo, 2008.

ROBERTS. J. A.; JONES, E. Money attitudes, credit card use, and compulsive buying among American college students. The Journal of Consumer

Affairs, v. 35, n. 2, p. 213-240, 2001.

SHEFRIN, H.; NICOLS, C. M. Credit card behavior, financial styles, and heuristics. Journal of Business Research, v. 67, n. 8, p. 1679-1687, 2014.

SOCIEDADE BRASILEIRA DE PROTEÇÃO AO CRÉDITO (SPC). Pesquisa de Inadimplência.

Disponível em: < http://www.acsp.com.br/ indicadores/indicadores.html >. Acesso em: 25 mai. 2014.

TAN, A. K. G.; YEN, S.; LOKE, Y. J. Credit card holders, convenience users and revolvers: a tobit model with binary selection and ordinal treatment. Journal of Applied Economics, v. 14, n. 2, p. $225-$ 255, 2011.
TEOH, W. M. Y.; CHONG, S. C.; YONG, S. $\mathrm{M}$. Exploring the factors influencing credit card spending behavior. among Malaysians. International Journal of Bank Marketing, v. 31, n. 6, p. 481-500, 2013.

ZERRENNER, S. A. Estudo sobre as razões para a população de baixa renda. $57 \mathrm{f}$. (Mestrado em Administração) - Universidade de São Paulo, São Paulo, 2007.

WANG, L. B.; WEI LU, A.; MALHOTRA, N.; K. Demographics, attitude, personality and credit card features correlate with credit card debt: a view from China. Journal of Economic Psychology, v. 32, n. 1, p. 179-193, 2011.

WARWICK, J.; MANSFIELD, P. Credit card consumers: college students' knowledge and attitude. Journal of Consumer Marketing, v. 17, n. 7, p. 617-626, 2000. 